ON

DISEASES OF THE KIDNEY

ACCOMPANIED BY

A L B U M I N U R I A,

CONGIDERED IN RELATION TO

THEIR ORIGIN IN CHANGE OCCURRING IN THE TUBES OR IN THE INTERTUBULAR STRUCTURE.

BY

W. H. DICKINSON, M.B. CANT., M.R.C.P.,

MEDICAL REGISTRAR AND DEMONGTRATOR OF ANATOMY AT ST. GEORGR'S HOSPITAL.

Received March 21st.-Read June 26th, 1860.

Several years ago I collected some evidence upon the subject of Bright's disease, believing that the kidney which was once large, mottled, and glossy, required nothing but time to become shrivelled and granular. I soon met with facts which compelled me to renounce this opinion, and to assume that the two conditions involved quite different changes. Believing that morbid anatomy must be the foundation of all sound pathology, I have since applied myself to the minute examination of the kidney under its various aspects of health and disease, and the results $I$ have obtained will form the basis of the present paper.

I believe I shall be able to show that all those conditions of kidney which have been called after the name of Dr. Bright, whether rough or smooth, large or small, whatever their external appearance may be, are capable of arrange-

xLIII. 
ment into two great classes; that in the one we have disease proper to the secreting surface of the tubes, while in the other the disease is essentially intertubular; and that the great characteristic difference between these two morbid conditions is, the absence or presence of superficial granulation.

I will commence by endeavouring to explain the patinology of the former of these complaints, where the surface of the kidney remains even. This I will venture to call the-

Tubular Disease.-I shall include, in a general description, all the varieties of the large smooth kidney, regarding as unimportant all those distinctions which depend on the quantity of oil which happens to be in the epithelial cells, or of fibrinous matter in the tubes.

This state of kidney has been well explained by $\mathrm{Mr}$. Simon, in a paper read before this society. In the progress of the disease may be recognised two distinct stages. First, the period of enlargement; secondly, the period of diminution.

But, before undertaking to describe the minute anatomy of either of these conditions, I may be allowed to explain the methods $I$ have used in the investigation. Besides the ordinary plan of tearing the organ into shreds with needles, and looking at the component parts under a high power, it has been my habit to prepare translucent sections of the gland, made in such a way as to show the tubes and the Malpighian bodies in their living relation to each other, and to the intertubular material. A piece of the kidney is boiled in water, slightly acidulated with acetic acid; it is then hung up to dry, and in a short time acquires much of the appearance and texture of gutta percha. If a smooth surface be now cut, and then moistened with a drop of water, it will be found that, from this damp surface, sections can be obtained of any degree of tenuity, which will present a beautiful picture of the anatomy of the kidney. These require a magnifying power of from 80 to 100 diameters. Plate VII is a good representation of such a section, taken from a healthy kidney. 
Much that I shall set forth has been deduced from examinations conducted in this way. A person who wishes to obtain a knowledge of the structure of any organ, may spend his life in picking it into small pieces, and looking at the component parts under a high power, without ever being able to do more than enumerate the elements of which it consists. His microscopic eye cannot appreciate the relationship of the several parts. It is essential that some method should be devised which shows more of the organ as a whole; in its habit as it lived; with its elements bearing their natural relation to each other. Now I think I shall be expressing the conviction of many of my readers, when I say that ordinary dexterity is quite insufficient to obtain a section of the fresh kidney which answers this purpose; but when prepared in the way I have described, the section is made so easily, and is so clear, that nothing remains to be desired.

Returning now from this necessary digression, I will endeavour to unfold the pathology of the large smooth kidney. From the commencement of the disease, the gland gradually increases in bulk; its weight is often more than doubled. Sometimes in the earlier periods a certain amount of congestion is visible, but this soon becomes masked by the opaque epithelium which is the cause of the enlargement. The characteristic aspect of bloodlessness, which belongs to the disease, may be produced in as short a time as four days. I shall presently show that this anæmia is more in appearance than in reality, and that excessive secretion is the essence of the disorder. If the complaint has, as yet, made but little progress, there will be seen on section a coarseness of texture, an appearance as of two materials, a red and a buff, roughly intermingled, and often sprinkled throughout with red points, which are injected Malpighian bodies.

As the disease progresses, the appearance becomes more characteristic. The surface invariably remains perfectly smooth, and the capsule loose and thin as in health. When this investment is removed, little or nothing is seen of the 
superficial capillaries which should divide the surface into lobules. There is great apparent want of vascularity, but here and there may be seen a patch where red vessels are visible on the surface, and the kidney is accordingly described as mottled. When cut open, it is seen that the cortex is greatly increased in bulk; the cones usually being enlarged too, though seldom to a corresponding extent. The cortical substance varies much in appearance, according to the nature of the secretion which distends the tubes. It is sometimes, particularly when the disease has followed scarlet fever, almost like ivory in colour and fineness of texture; generally it has a yellow tinge and coarser grain, and resembles the cut surface of a parsnip. In the former case the tubes will be found stuffed with healthy epithelium; in the latter, the cells have undergone more or less fatty degeneration. The cones sometimes retain their ordinary appearance, which is exaggerated by contrast; usually they are paler than in health, owing to the same sort of change as has affected the rest of the organ. Such are the appearances which may be observed by the unassisted eye in well established cases of the tubular disease. I will endeavour to explain the elementary changes to which they are due.

If we examine a section of a kidney in this condition, prepared in the way I have already advocated, we shall find the organ anatomically complete. The tubes are all entire and everywhere in contact with each other; they may appear a little swollen, but with the low power used this change is not very manifest. The Malpighian bodies are everywhere at the usual distance apart, showing that there has been no loss of renal substance; and, on the whole, the drawing No. 1, which is an excellent representation of a healthy kidney, may pass for a portrait of this stage of tubular disease. From an examination thus conducted, our information, is in this instance, of a negative character.

With higher powers and the fresh kidney, we find the disease to be essentially of the tubes. The ducts which compose the cortex are invariably choked up with,their own secretion, perhaps here and there discoloured with blood. 
The cells may remain entire or may be more or less broken down. They are more apt to lose their integrity when there is a tendency to fatty degeneration. Sometimes nothing can be seen in the tubes but the oil globules, into which the altered cells have broken. In twenty-two characteristic specimens of the disease, it was found that the matter distending the tortuous ducts, was the epithelial secretion of the organ, and that only, save in a solitary instance, where a little fibrinous matter was found. This epithelium is in most cases, more or less fatty, and more or less broken down. Unbroken and unchanged cells were found in seven cases; but in only one of these did they exist to the exclusion of everything else. In sixteen, the ducts contained fatty epithelium, this being generally much disintegrated. Out of the whole number, it appeared that the distension of the organ was due about as much to the presence of comminuted cells, as to that of unbroken ones. The frequency of these changes, as affecting the cortical structure, may be thus stated :

Table showing the contents of the convoluted tubes in twentytwo cases of large smooth kidney.

\begin{tabular}{|c|c|c|}
\hline Entire cells alone in 4 & - & $\left\{\begin{array}{l}\text { These containing oil in } 3 . \\
\text { Not containing oil in } 1 .\end{array}\right.$ \\
\hline Intire and broken & gethe & $\left\{\begin{array}{l}\text { With oil in } 12 . \\
\text { Without oil in } 3 .\end{array}\right.$ \\
\hline Zroken colle & & $\left\{\begin{array}{l}\text { With oil in } 1 . \\
\text { Without oil in }\end{array}\right.$ \\
\hline 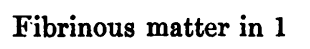 & & With oil and $b$ \\
\hline
\end{tabular}

A fatty condition of the epithelium is very much more common with the smooth kidney than with the granular. It is probable that it is a consequence rather than the cause of the derangement. Possibly the tube membrane is altered by the inflammation or congestion which constitutes the disease, and is rendered apt to produce cells slightly erroneous in composition, so as either to contain oil originally, or to decompose into oil soon after their detachment.

I have observed that when the disease has followed scarlet 
fever, there is little tendency to this degeneration; but when it has come on in consequence of a definite exposure to cold, then, almost invariably, oil forms the bulk of the tubular contents. In other organs, as in this, oil often appears as the result of inflammatory action. If we peel the layer of fibrine from the surface of a heart affected with pericarditis, the superficial muscular fibres often appear to be transformed into oil globules, while those placed deeper remain in their natural condition. Similarly oil is developed in the lung under pneumonia, and probably in the brain under the influence of inflammatory softening; but it is not necessary to multiply examples of a sequence which is familiar to all pathologists. Such facts show the likelihood that "fatty degeneration of the kidney" is not a specific and independent disorder, but is merely an occasional accompaniment of the tubular disease, which essentially consists in increased epithelial growth, depending on inflammation or some allied condition.

In the later stages of this disease, a considerable quantity of pus is sometimes found in the urine, which has obviously been secreted by the tubes. Pus globules are seen imbedded in the casts, and after death the same product is found in the ducts. In one and the same case may be seen'sometimes all the intermediate links by which the normal epithelium has become thus altered.

Whatever be the state of the kidney, whether smooth or granular, cells are occasionally observed in the urine, which at first look like natural glandular epithelium, but under the action of acetic acid exhibit the compound nucleus characteristic of pus. But in the smooth kidney alone is this secretion ever found in sufficient quantity to attract attention. It here sometimes forms a deposit obvious enough to the unaided eye. In the granular kidney, the only trace of its existence consists in a few scattered cells only to be recognised by microscopic research, and after subsidence.

With regard to the breaking up of the epithelium, I may observe that the integrity of the cells is the measure of the acuteness of the disease. Where that secretion has lost its 
form, it may be presumed to have remained long in the tubes. In five well-marked cases of the disease, where the distending material was almost entirely unbroken epithelial cells, the duration of the symptoms had varied from three weeks to four months. In the same number of cases, where the secretion was chiefly comminuted, the disease had endured for periods varying from three months to thirteen years. In the former class the average duration of the disorder was less than ten weeks, in the latter it was more than three years. These statements are of course drawn entirely from the examination of the organs after death; but the rule deduced can be easily applied during life by examining the sediment thrown down by the urine. This part of the question, however, is foreign to my present purpose.

A few words upon the state of the tubes in the cones will conclude what $I$ have to say upon the anatomy of the large smooth kidney. These channels being straight, and comparatively short, are little liable to become blocked up.

The products of disease, whether formed within their own cavities, or brought from afar, find a ready exit. Hence it is that the epithelial secretion, which is filling up and spoiling the tortuous ducts, is never present in the same quantity in these, and is frequently absent altogether. It is not unusual to find most of the tubes here perfectly healthy. It appears, however, that generally there is the same tendency to perverted secretion as elsewhere. The morbid product is washed from the surface, and the membrane is afterwards found perfectly bare. Thus, the straight portion of the duct is often in an opposite condition to the convoluted. Instead of being permanently obstructed and impervious, it is continually becoming filled up with a glossy fibrinous material, which is repeatedly shed in the form of cylinders. Probably, owing to some change in themselves, the interior of these casts becomes generally studded with specks of oil-or cells of epithelium, or bloodcorpuscles, which chance to be travelling downwards, may become imbedded. The epithelial product may be in such 
large quantity as to form the bulk of the cylinder. There can be no doubt that it is mainly in this portion of the gland that casts are produced; for in cases where, for long before death, these productions have all been transparent and glassy, it is very common to find the cortical ducts all choked with coarse, opaque secretion; while in the cones alone is found abundance of the material of which the casts are formed. Besides this, I think we may fairly conclude that in this complaint the cones undertake part of the secreting duty of the organ. The convoluted portion of the tubes are seen crammed with stale secretion, so that they must be perfectly impervious. The casts which were shed, perhaps, may have contained nothing but smooth, glassy fibrin, so that none of the opaque epithelial product could have escaped; and the tubes so circumstanced must have been devoid of any power of secretion. This conviction is further borne out by an examination of the cones themselves; for, in such cases, not only are they frequently of greater extent than usual, as if they had undergone some sort of compensating hypertrophy, but their epithelium is sometimes obviously changed in character, it becomes fuller and more rotund, like that proper to the cortical structure.

Before quitting this portion of my subject, I must briefly notice an unusual form which the disease sometimes assumes. The surface of the gland, instead of being nearly uniform or mottled, so that the shades run into each other, is speckled all over with little, sharply defined, white spots, which look like something foreign to the substance of the organ. These are not, as at first they appear, intertubular, but are little families of tubes, densely filled with fatty epithelium ; the ducts between them being affected to a much less degree, or even remaining natural. This condition, however, is so rare as not to demand further discussion.

I will now proceed to sketch what I believe to be the second stage of the tubular disease.

We have traced the progress of the renal catarrh, if I may be allowed the expression, from its commencement, in excess of epithelial growth, to its climax in total obstruction 
of the cortical tubes. The next step is a simple one. The over-stretched tubes, one after another, burst, and their contents, no longer secluded by a surrounding membrane, are brought within the ready operation of the absorbents and are removed. This, however, is a matter of inference rather than of demonstration. Examining in section a number of enlarged smooth kidneys, I found that about half of them had thus commenced to pass from the stage of enlargement to that of decrease, although there was nothing in their outward appearance to indicate it, their bulk still being excessive. A section, taken from a kidney in this state, is represented in the drawing No. 2. The pair weighed sixteen ounces. In such preparations we find places, especially near the surface, where the Malpighian bodies, which have now become enlarged, and enveloped by condensed fibrous tissue, lie in unnatural proximity. Often several almost touch each other. Their intervals are occupied by the debris of collapsed and ruined structure. Shrivelled remnants of the tube-membrane are generally clearly seen. This condition is as yet only partial. A distended duct is often seen winding among the wasted remains of its companions. The tubes, one after another, collapse until a great portion of the once enlarged gland has been reduced to the bulk of little more than its Malpighian bodies. The appearance of the organ affected has by this time undergone some alteration. It has lost its excess of bulk, and even shrunk below the natural size; in one case a single kidney weighed only an ounce and a quarter. The capsule has generally become thickened to a slight degree, and become more disposed to adhere than formerly. The surface remains perfectly even, but often presents to the eye a fine, sandy texture. The colour has undergone but little change. It is still pale, greyish, and apparently wanting in blood. When the organ is cut open, it is manifest that it is chiefly composed of cone substance; an edge, perhaps, no thicker than a shilling, being all that separates that structure from the capsule. What remains of the cortical material is coarse in texture, pale and firm. 
The condition I have just described, that of the smooth, dwindled kidney, is seldom attained; though, as I said before, the process which leads to it has been commenced in about half the cases of large, smooth kidney which reach the dead-house. During ten consecutive years, 2350 bodies were examined in St. George's Hospital, and this condition of the renal organs is described only in twelve instances.

A magnified section of a kidney, where this change was fully developed, is represented in plate No. 3 ; it is a step beyond what was seen before. In such kidneys the peculiarities are weil seen by the method made use of. There is close aggregation of the Malpighian bodies; and the fibrous tissue of the organ is condensed around them. The spaces between them are occupied by structure wasted and collapsed, even until it approximates, in some places, to mere fibrous tissue. A few of the tubes are left; and these sometimes intermingle pretty uniformly with the effete remains, and at other times are gathered together into insular masses. The destructive change shows a predilection for the more superficial parts of the organ; it begins at the surface and proceeds inwards. This is what we should expect. A gun barrel bursts near the breech, and the convoluted tube of the kidney gives way at the part furthest removed from its orifice.

Higher magnifying powers and the fresh kidney corroborate these statements, and enable us to add a few particulars. We find that healthy tubes, or, indeed, tubes of any sort, are difficult to meet with; while the mass of the organ presents the appearance of coarse, fibrous tissue, mixed with fibrillating cells, in the midst of which can occasionally be seen natural and shrivelled tubes. There is no reason to believe that there is any unnatural formation of fibrous tissue; this material necessarily forms the bulk of the kidney on the removal of the contents of the ducts. In one of the few specimens of the disease which I have seen, little cysts were so numerous as to give to some parts of the cortex the appearance, under the microscope, of a sponge. The cones were similarly affected, but to a less degree. The arrange- 
ment and size of these cysts were such that they could scarcely have been produced by division of the tubules. They were placed rather in nests than in lines, and some were no more than $\frac{1}{1430}$ of an inch in diameter. It seems that the theory put forth by Mr. Simon here holds good. The cysts are developed out of the epithelial germs which are left on the walls of the ruptured tubules. I shall, hereafter, show that under different circumstances cysts are formed in a different way. This brings to an end what I have to say upon the anatomy of the smooth, mottled kidney. I will now pass on to the granular or intertubular disease.

It will be convenient to describe first a most important stage, that of commencement; marking the earliest signs by which the intertubular effusion may be recognised. This, I hope, will tend to throw light upon the subsequent progress of the disease. This done, I shall take leave to divide granular kidneys into two families, and in so doing $I$ shall study convenience rather than strict pathological accuracy; for, though extreme cases are different enough, these are merely the terminal links of an unbroken chain. I may be allowed to speak of these as the chronic and the acute varieties of the intertubular disease.

First, then, as to the period of commencement. It is common to meet with kidneys as to which there is a doubt whether they are healthy or not. The capsule is a little thickened, and it is more adherent than it should be. When removed, the surface presents a confused, muddy appearance, and it may be noticed that a thin layer of capsule is still adhering to the kidney. As yet there is no distinct granulation, though the tendency may be indicated by one or two curved depressions, or by a little general roughness. On examining such a kidney, in section, we shall find all the central parts quite healthy, save that closely attached to the inner capsular film; we shall see certain narrow projections insinuating themselves between the tubes. If we observe the position of an external depression or cicatrix, we shall find that from this passes 
inwards a process of fibrous-looking material, which is seen to involve in its interior the contracted remains of tubes it has imbedded in its passage. It looks as if an effusion, small in amount, had commenced in the surface and worked its way inwards among the ducts, numbers of them thus becoming completely surrounded. After a time contraction follows in the wake of the exudation, and the tubes imbedded are reduced to mere microscopic threads. At the same time appears another result of the contractile tendency. The points at which the processes originate become depressed; and when these are numerous and tolerably regularly distributed, the result is superficial granulation.

As we daily see, the tubes themselves may be distended to the last degree, the surface of the organ still remaining perfectly smooth and glossy. And we should be at a loss to explain how it should be otherwise. The cortical substance is a uniform entanglement of ducts, twisting through meshes of fibrous network, which are so minute that they are far beyond the range of any eye but the microscopic. And when the swelling of the kidney is limited only by this network, and by the distensibility of the tubes themselves, a surface must be produced which is to the eye and touch perfectly smooth. To produce a puckered or granular surface, we must have something else. It is essential that there should be some means of tying down the surface at numerous points, between which only is expansion possible. This condition is provided in the manner I have endeavoured to explain.

The earlier kidneys are examined in this disease, the larger they are. At the very commencement of granulation I have found them weighing together sixteen ounces. As. contraction proceeds they become, as is well known, much below the natural size.

The foregoing observations may be verified upon the prepared section with a low power. If now we resort to the quarter-inch object glass, and examine the tubes at the earliest period at which we can surely recognise the disease, we may find all the tubes perfectly natural, and the epithelium 
exactly what it is in a state of health. More commonly we shall find some of the tubes healthy, while others are filled with whole or broken down epithelium; this being sometimes, especially in the cones, visibly intermixed with transparent material. It will be seen, hereafter, that the prevalence of this glassy matter in the convoluted tubes is one of the characteristics of the intertubular disease. This is suggestive of an explanation. As effusion takes place between the tubes; it easily drains through the thin, basement-membrane, and dislodges the epithelium upon it. After a time the cells cease to be reproduced, and the tube remains naked, containing only the transparent, fibrinous portion of the exudation.

It has been supposed that this disorder essentially consists in a degenerative change in the epithelial cells, but my own observations have abundantly convinced me that this is not the case, the cells in the earlier stages of the complaint being usually exactly what they are in a state of health. The epithelial cell loses its character very soon after death. In kidneys, apparently healthy, we always find that a certain proportion of the cells have suffered the loss of their outer coat, so that they are seen as mere nuclei. This is probably a post-mortem change, and it is not more common in granular than in healthy kidneys.

I have alluded to some of the essentials of the disorder in speaking of its earliest stage. I will now give a brief summary of the results of the intertubular disease when it assumes a chronic form.

A very general result of this change is a diminution in size; the kidney often being no more than a third of its original weight. The capsule is thickened and adherent, as in the earliest stage, and manifests a tendency to split into two layers, leaving upon the kidney a very thin film, hard to separate from the renal substance. I have fancied that this may owe its existence, not so much to a splitting of the original capsule, as to an effusion from the surface of the kidney becoming converted into an inner vesture, more or less closely attached to the outer. If there be here an 
intertubular exudation, there is nothing but the pressure of the capsule to prevent the effusion showing itself superficially. On the removal of the capsule the surface is seen to be uniformly and finely granular, often looking as if each of the little fictitious lobules on the surface had become depressed at the edges. The colour remains pretty much what it was in health, or has more of red mingled with the natural brown. On section the diminished cortical structure presents a coarse texture, which, with its dirty-red tint, often reminds one of sandstone. Cysts, large and small, are frequently observed.

With this state of kidney, I may remark, in passing, that the urine may contain little or no albumen, and that there is usually no dropsy, nor, indeed, any other direct indication of its presence. It often appears as one of the accompaniments of age. I dwell upon it here, chiefly because it supplies a convenient step to the exposition of the more noticeable forms of the granular disease, although it is by no means devoid of clinical interest.

In a magnified section we find that all the central parts of the organ look natural, but near the surface the characteristic changes manifest themselves. Sometimes narrowpointed processes of fibrous material are seen passing a little way into the kidney from the intergranular depressions. If these alone are seen it may be inferred that the specimen is a very early one. Generally the section shows in the same position the contracted remains of the tubes imbedded in some sort of effused matter. Occasionally these contracted remains are all that indicate the path of the exudation. We may presume that this destruction of tubes is not owing to any disease within themselves, for the change extends quite independently of the direction they take. It usually follows a straight course inwards, irrespective of the bends and tortuosities of the ducts. If the section happens to come across a vessel, it will be seen that it is surrounded by an increased quantity of fibrous tissue. The capillaries are thus obstructed, and the transmitting power of the organ proportionally reduced. (Plate IX, fig. 1.) 
With the fresh kidney, and a high power, we may add a few particulars. Some of the tortuous ducts are in a natural condition; mingled with them are others irregularly filled with their own secretion in a comminuted state. This is a very constant condition, and is I believe essential to the disease. Excepting that transparent fibrinous matter is sometimes found in the straight tubes, the state of the cones is much the same with that of the cortical portion. There is to be observed the same predominance of natural structure, and the same irregular occurrence of ducts containing granular matter. The condition of the tubes is in some respects the same as with the smooth kidney. The main point of distinction appears to be this: In the smooth kidney we have an excessive secretion of epithelium which is universal, affecting alike all the secreting structure. With the granular we have an irregular shedding of the epithelium, which is only partial, some ducts being affected while their neighbours escape. This is exactly. what we should expect as the consequence of an intertubular effusion taking place at intervals through the organ.

In the chronic granular kidney, cysts are often developed. They are of various sizes, but chiefly of rather greater diameter than the tubes. Occasionally they are as small as the smallest. In texture they exactly resemble the ducts among which they lie. In the cones they are frequently clongated, and placed end to end, where, to compare great things to small, they much resemble a string of sausages. No impartial observer can doubt that in granular kidneys they result from the transformation of tubes. It seems impossible that they should be constructed merely by the blocking up of the ducts. The secretion which fills them is of course incapable of organization. It is necessary, therefore, that before a continuous cell can be produced, their sides must be brought into contact and must grow together. This can only be done by external pressure exerted upon the tubes at intervals, and the gradually contracting matrix of the kidney at once supplies the coudition.

I shall now proceed to indicate wherein what I have 
called the acute granular disease, differs in its results from the chronic. As one variety passes by imperceptible steps into the other, it is not very easy to fix a line of separation; although well-marked cases of each are sufficiently distinct, both in their morbid anatomy and in their effects on the system.

The condition of kidney which I have now to describe, unlike what I have called the chronic intertubular disorder, is always accompanied with albuminous urine, and generally with some degree of dropsy or some other obvious indication of deranged function. It is characterised by an irregular surface, covered with prominent light coloured granules, which project from a purplish ground. Sometimes light buff is the prevailing colour both of the elevations and depressions, the hue of course varying with the degree of congestion. These granulations vary in size, being commonly about one sixteenth of an inch in diameter. They are larger and more distinct than in the other variety of intertubular disease. On section, the cortex generally narrowed, looks as if made up of two materials coarsely intermingled, often reminding one of the texture of fine granite. Cysts are of very general occurrence.

A magnified section of a kidney in this condition is represented in the drawing, No. 5. The morbid appearances existing in the chronic form are found here further advanced. There is an obvious increase of fibrous tissue in the organ. Next to the capsule is often seen a mass of structure, in which all the renal elements have disappeared except the Malpighian bodies, which present more resistance to the compressing agency than the tubes. The ducts which remain are apt to be irregularly dilated. Occasionally may be seen passing into the organ a narrow portion of exudation which at first displays no tubes in its interior, but as it advances becomes spread out so as to include them, and when it is about to cease, its extent may be indicated only by a dark shade over the renal structure.

By the more usual, though less comprehensive, method of examination, we learn that a great characteristic of this form 
of disease is the peculiar condition of the cortical tubes. When the disease has lasted for any length of time they become devoid of lining, and appear either empty, or filled with glassy matter. This condition must necessarily take some time to become developed; the longer the complaint has lasted the more bare the tubes become. Taking nine well-marked cases, this process of denudation was found to have commenced in all but two. The fibrinous matter in some cases had become thickly sprinkled in its interior with oil-globules, the result of some change within itself. This, of course, is seen mingled with the natural growth in the earlier stages of the disease. The presence of the glassy material in the convoluted tubes, instead of, as in the smooth kidney, their own epithelium, can be conjecturally accounted for. If we suppose a fluid effusion to arise from the capillaries or from the fibrous skeleton of the organ, among and between the tubes, we should expect it to soak through the thin tube-membrane, and undermine and remove many successive crops of epithelium. In the more acute cases, the cells, at length, cease to be reproduced, and the tubes become filled with the fibrinous infiltration.

The ducts which compose the cones exhibit the same changes, but to a less extent. Usually some tubes remain unaffected by the disease, a few may contain disintegrated epithelium, but, as in the cortex, the greater number are empty or filled with translucent fibrinous material.

It is worth observing that in granular kidneys the tubes, of both kinds, are more difficult to isolate than in the smooth. Any one who has been in the habit of scratching the texture into shreds, for microscopic examination, cannot fail to have noticed this.

This sketch of granular disease of the kidney would not be complete without a few words upon the condition of the epithelium, especially as the complaint has been supposed to consist essentially in an atrophy or degeneration of the secreting cells. Much that $I$ have already said tends to show that this is not the case. I carefully examined the epithelium in twenty-seven granular kidneys, taken without 
selection as they occurred in the dead-house. In five of these the cells contained more or less oil. The quantity was generally small. This is different from what is found in the other forms of renal disease, where the epithelium contains oil in two out of three cases. In five others of the specimens so examined, a certain quantity of oil was found in the tubes, though none could be seen in the separated epithelial cells. This probably had been developed in the fibrinous exudation I have before spoken of.

I have not been able to detect any other change in this portion of the organ. I have carefully compared the epithelium from granular kidneys with that from the same glands in a state of health. In both kinds I have found it to vary much - being sometimes granular, ragged, and ill defined; and sometimes, especially when decomposition has commenced, showing nothing but little sharp-edged bodies, spherical or ovoid in shape, which are the isolated nuclei. I have not been able to find that these conditions are more frequent in diseased than in healthy kidneys, and I believe them to be the result of post-mortem change.

In conclusion, I wish to give briefly the results of some experiments upon circulation in the kidney in health and disease. At the suggestion of Dr. Bence Jones an apparatus was arranged by which water could be poured into the artery of different kidneys under the same circumstances as to pressure, temperature, and size of orifice. The quantity of fluid which then escaped from the vein in a certain time was taken as affording a measure of the permeability of the capillary system in each case.

A cistern containing a definite quantity was so placed as to give a column of water with a fall of eight feet four inches. This was discharged into the kidney which was the subject of the experiment, through a flexible tube terminating in a metal nozzle of such a size as to enter a renal artery of the smallest calibre. The water in the cistern was always heated to $110^{\circ}$, for it was found that then the loss of heat in the tubes was such that the fluid passed through the organ with the least attainable variation 
from $99^{\circ}$, which was taken as blood heat. The kidneys were all supported in the same position, and they were all operated on at not less than thirty-six hours after death, and before there was any evidence of decomposition. Water was in this way conducted through thirteen healthy kidneys, through five well-marked specimens of the large smooth variety, and through six equally definite examples of granular degeneration. The following table shows the quantity of water which passed through the organ in ten minutes in each case, and gives at the same time the weight of the kidney which was the subject of the experiment:

Table showing discharge from vein in ten minutes.

\begin{tabular}{|c|c|c|c|c|c|}
\hline \multicolumn{2}{|c|}{ HEALTHY. } & \multicolumn{2}{|c|}{ LARGE SMOOTH. } & \multicolumn{2}{|c|}{ GRANULAR. } \\
\hline Weight. & Discharge. & Weight. & Discharge. & Weight. & Discharge. \\
\hline $\begin{array}{l}5 \overline{\frac{1}{4}} \text { oz. } \\
7 \frac{1}{2} \\
8 \\
5 \frac{8}{4} \\
4 \frac{8}{4} \\
5 \\
7 \frac{1}{2} \\
6 \frac{1}{2} \\
5 \frac{8}{4} \\
7 \frac{1}{2} \\
6 \frac{3}{4} \\
7 \frac{1}{2}\end{array}$ & $\begin{array}{c}53 \text { oz. } 1 \mathrm{dr} \text {. } \\
59 \\
220 \\
52 \\
84 \\
105 \\
90 \\
221 \\
61 \\
72 \\
145 \\
200 \frac{1}{2} \\
196 \frac{1}{2}\end{array}$ & $\begin{array}{c}11 \mathrm{oz} . \\
11 \frac{1}{2} \\
10 \frac{1}{2} \\
7 \text { (at. 12) } \\
9 \frac{1}{4}\end{array}$ & $\begin{array}{c}129 \frac{1}{2} \text { oz. } \\
89 \frac{1}{2} \\
81 \\
66 \frac{1}{2} \\
86\end{array}$ & \begin{tabular}{|c} 
“Shrunk" \\
6 oz. \\
6 \\
$2 \frac{1}{2}$ \\
4 \\
$4 \frac{3}{4}$
\end{tabular} & $\begin{array}{ll}40 \text { oz. } 5 \text { dr } \\
15 & \\
22 & \\
4 & 6 \\
26 & \\
43 & \end{array}$ \\
\hline
\end{tabular}

From this it appears that, though great variation exists within the limits of health, yet the effect of disease is sufficiently obvious. The average discharge of the healthy kidney proved to be about 119 ounces, the smallest amount being 52 ounces, the largest 221 ounces. The circulating powers of the large smooth kidney do not depart very notably from this - the escape varying from $66 \frac{1}{2}$ ounces, which was in the case of a child, to $129 \frac{1}{2}$. Thus it appears that the large mottled kidney allows the normal quantity of blood to pass 
through it, although its transmitting power is not commensurate with its gain in size. This is what might have been expected, considering that the increased weight is merely due to accumulated secretion. The appearance of anæmia results, not from absolute deficiency of blood in the organ, but from the quantity of opaque epithelium by which the blood-vessels are separated.

With the granular kidney the results are more characteristic. The average flow here was little more than 25 ounces; less than a quarter of what it is in health-the kidney where the obstruction was greatest discharging only 4.3. The smallest quantity delivered by the healthy organ was 52 ounces; by the large smooth variety, $66 \frac{1}{2}$. With the granular the greatest did not reach either of these amounts, being only 43 ounces. In a specimen not far removed from health, where the granulations appeared to be just commencing, I found the discharge reached 56 ounces. I have not included this in my table, as not being a wellmarked case, the condition of the kidney being doubtful.

It is sufficiently manifest that, as a kidney becomes granular, it becomes impervious, and cannot, as a rule, receive more than a small part of the blood which should traverse it. The condition is, to use Dr. Prout's term, one of anæmotrophy. The obstruction to the circulation takes place in the ultimate vessels, and not in the main trunks. I have made careful measurements of the diameter of the vessels in granular kidneys as compared with those in health. I will not prolong this paper by needless details ; but I found that the internal circumference of the renal vessels could, in most cases, be accurately gauged at a spot between the final union of all the vessels from the gland, and the attachment to the aorta or vena cava. Measuring at this spot, I found the internal circumference of the artery in health varied, in thirteen cases, from 0.45 to 0.75 inch. The corresponding vein was ascertained in eleven cases. It varied from 1.07 to 1.52 inch. Now, in the granular kidney, which discharged only $4 \frac{1}{2}$ ounces, the artery measured $0 \cdot 45$, the vein $0 \cdot 94$. In the specimen which delivered 26 ounces, the artery 
measured 0.46; the vein, 0.91 inch. And in other instances I have found the measurements almost identical with these. Thus it appears that the blood-vessels are of somewhat diminished capacity, especially the vein, but that the diminution is utterly insufficient to account for the impediment to the circulation. The slight narrowing of the trunk-vessels is probably due to the power they have of adapting themselves to the smaller quantity of blood which is passing through them. The pressure of blood upon the artery, of course, is what it always was, while that upon the vein is diminished as the capillaries of the organ become obstructed.

The chain of anatomical evidence in favour of the intertubular origin of the disease which produces the granular kidney is tolerably complete. It may be thus summed up :

1. Near the surface an effusion is often seen obviously between the tubes. This accounts for the superficial granulation, and bears out the analogy between granular degeneration of the kidney and cirrhosis of the liver.

2. Tubes are caused to shrivel by some influence which travels independently of their direction.

3. Tubes are sometimes divided into cysts. This can only be accomplished by a contractile force external to themselves. In the smooth kidney this never occurs.

4. In most cases some of the secreting tubes are found natural, as if they had been out of the way of the effusion, whereas in the smooth kidney all are commonly involved.

5. A decided difference exists in well-marked cases of each sort in the contents of the tubes. In one they are filled by their own morbid secretion; in the other they are occupied by a material which is foreign to it.

6. In the granular kidney, as in the cirrhosed liver, some alteration takes place in the minute anatomy of the organ which impedes the passage of blood through it. This does not take place in the smooth kidney.

I will not tax the patience of the Society further at present. I hope to be allowed to bring forward some clinical facts in connection with the subject on a future occasion. 


\section{DESCRIPTION OF PLA'TES.}

Plate VII. Healthy kidney.

A section of the cortical structure, made in the manner described, showing the arrangement of the tubes and Malpighian bodies. The edge of the section corresponds with the surface of the organ (p. 226).

Plate VIII. Tubular disease.

Fig. 1. A section, made in the same way, from a large, smooth kidney, where, however, the process of shrinking had commenced. Some tubes are in a state of distension, while others have burst and collapsed (p. 233).

Fig. 2 shows the condition where the same changes have gone on to a further extent, producing much diminution of bulk. Some tubes are still swollen, but most are shrivelled. The Malpighian bodies are enlarged and irregular in shape; they are closely approximated, owing to the destruction of the tissue between them (p. 234).

Plate IX. Inter-tubular disease.

Fig. 1, showing the exudation in the chronic or partial variety. The inter-tubular effusion, giving a dark colour to the section, is seen commencing near the surface, which has become depressed in consequence. The tubes are compressed where the exudation has taken place; they may be recognised by their lighter colour. Out of its way they remain natural (p. 238).

Fig. 2. A section exhibiting the more extensive changes characterising the severer forms of the disorder. The inter-tubular effusion is well seen, starting at the surface, and becoming diffused as it proceeds inwards. The capsule still remains attached; close to it the processes of exudation may be seen palpably between the tubes (p. 240). 


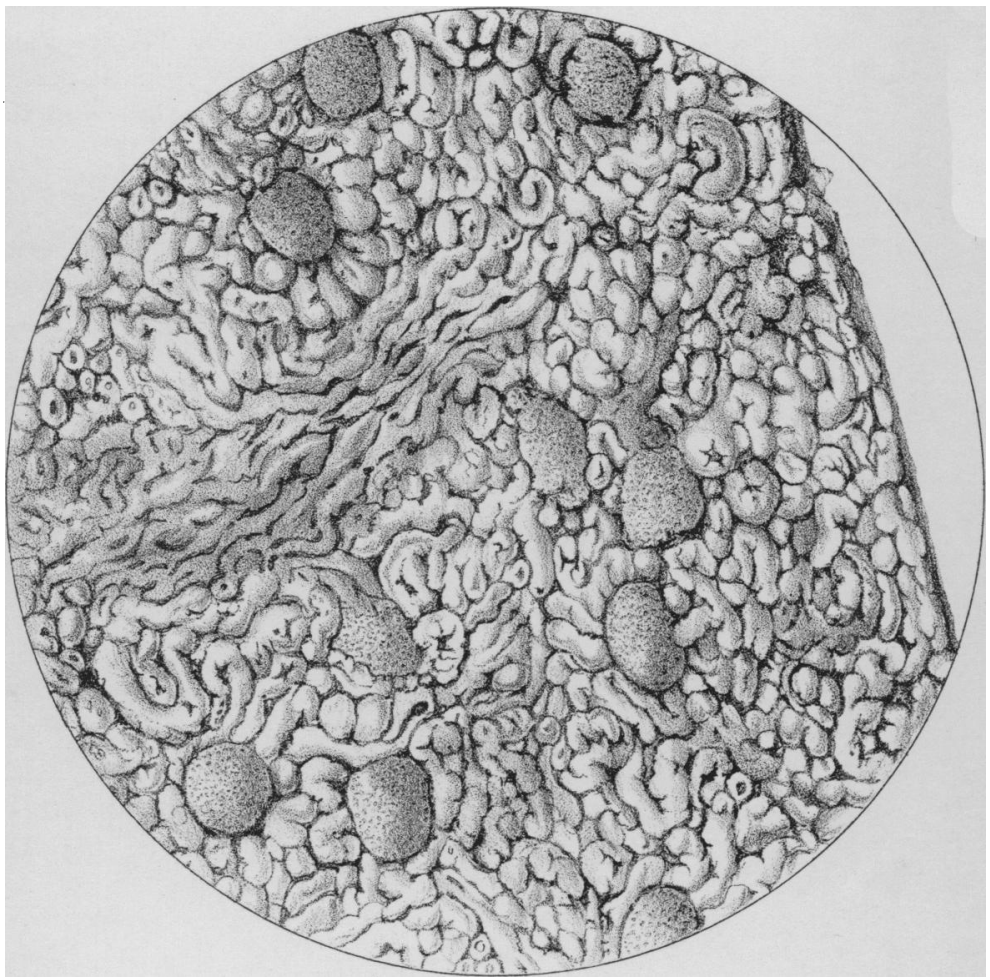

Magnified 75 Diameters.

Natural Condition 

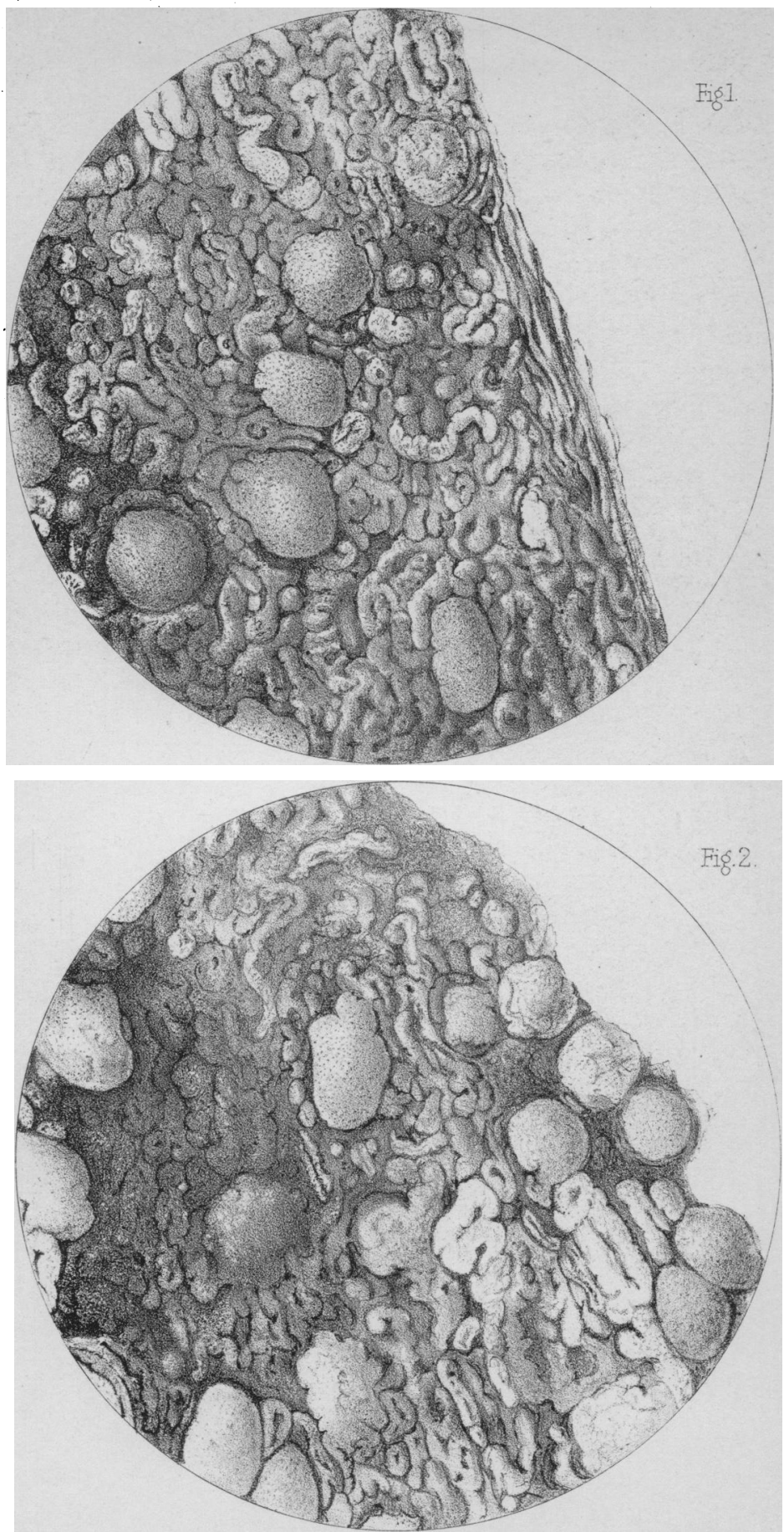

Magnified 75 Diameters. 

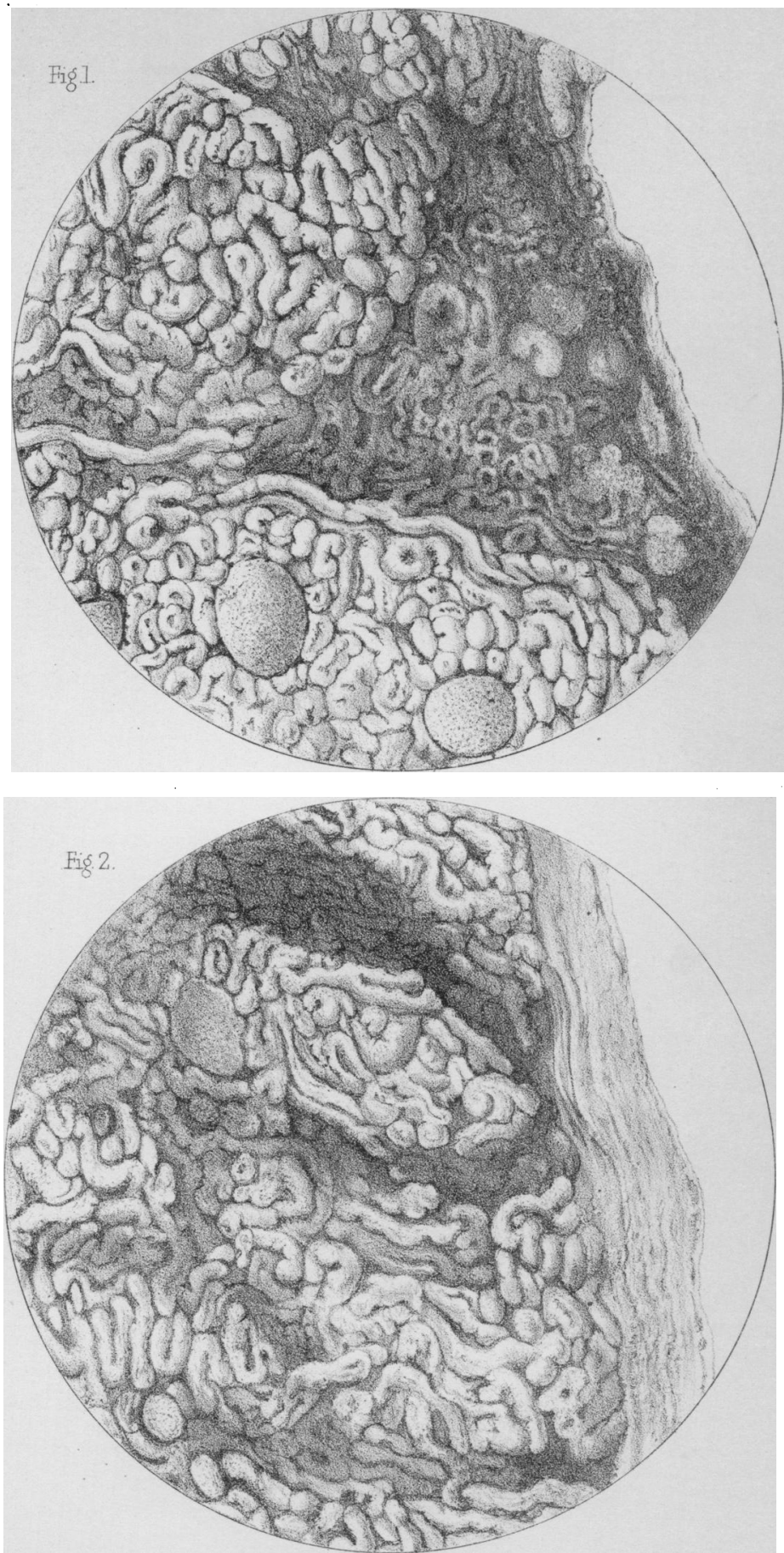

Maanified, 75 Drameters 